\title{
KLÂSIK EDEBIYAT BAĞLAMINDA ERZURUMLU İBRAHIM HAKKI DÎVÂNINDA ŞEHNAME KAYNAKLI UNSURLARIN KULLANIMI
}

\author{
Ömer İNCE ${ }^{1}$
}

\begin{abstract}
Özet
Divan edebiyatı, toplumsal hayatı ilgilendiren her türlü kültürel kaynaktan yararlanmıştır. Mitoloji de edebiyatın yararlandığı bu kaynaklardan biridir. İran dil ve kültürünün, Orta Asya ve Osmanlı sahası Türk dili ve Türk kültür ve edebiyatı üzerinde etkili olduğu bilinmektedir. Klasik edebiyat şairleri arasında gösterilen İbrahim Hakkı, dini-tasavvufi şiirlerinde Şehname kaynaklı unsurlara fazla yer vermemiştir. Klasik edebiyat şairlerinin özellikle kasidelerinde yoğun olarak kullandıkları bu malzemenin, Erzurumlu İbrahim Hakkı Divanı'nda az kullanılmasının sebebi, mutasavvıf bir şair olarak, dünya ve devlet adamlarından bir beklenti içerisinde olmayışı, bunun için devlet büyüklerine kaside sunmayışı olarak değerlendirilebilir. Bu sebeple genelde Klasik edebiyat şairlerinin devlet erkânını övmek için kasidelerinde teşbih ve telmih ilgisiyle çokça yer verdikleri mitoloji ve Şehname kaynaklı unsurlara, İbrahim Hakkı Divanı'nda fazla ihtiyaç duyulmamıştır. Ancak sınırlı da olsa şairin bu malzemeyi kullanması, onun dini-tasavvufi şiir dil ve üslubuna Klasik edebiyatın söylem özelliği katmasını sağlamıştır.
\end{abstract}

Anahtar Kelimeler: Tasavvuf, Klâsik edebiyat, Şehname, İbrahim Hakk1.

THE INCORPORATION OF ŞEHNAME RELATED THEMES IN THE COUNCIL OF IBRAHIM HAKKI OF ERZURUM IN THE CONTEXT OF CLASSICAL LITERATURE

\begin{abstract}
Divan literature; has benefited from all kinds of cultural resources concerning social life. Mythology is one of these sources that literature uses. Iranian language and culture is known to have an impact on Turkish language and Turkish culture and literature in Central Asia and the Ottoman area. İbrahim Hakk1, who is one of the poets of classical literature, did not give much place to the elements of Şehname in his religious-mystical poems. The reason why this material, which is used extensively by classical literature poets especially in kasides, is rarely used in the Divan of Ibrahim Hakk1 of Erzurum can be considered as the lack of an expectation from the world and statesmen as a sufi poet and not presenting it to the elders of the state. For this reason, the elements of mythology and Shahname, which the classical poets of classical literature give much attention to with praise and remembrance in praises of state authority, are not needed much in Ibrahim Hakk1 Divan. However, the use of this material by the poet, albeit limited, enabled him to add the discourse characteristic of Classical literature to the language and style of his religiousSufi poetry.
\end{abstract}

Keywords: Mysticism, Classical literature, Şehname, İbrahim Hakkı.

\footnotetext{
${ }^{1}$ Dr. Öğr. Üyesi, Dokuz Eylül Üniversitesi, Buca Eğitim Fakültesi, Türkçe ve Sosyal Bilimler Eğitimi Bölümü, e-posta: omer.ince@ deu.edu.tr
} 


\section{Giriş}

Erzurumlu İbrahim Hakkı, şair düşünür ve mutasavvıf olarak hem okur-yazar çevrelerde hem de geleneksel tarzda hayatını sürdüren halk arasında bilinen tanınan varlığını ilgiyle devam ettiren şahsiyetlerden biridir. Türk edebiyatında Mevlânâ (ö. 672/1273), Yunus Emre (ö. 721/1321) ve Hacı Bektaş-1 Velî (ö. 669/1271?) gibi din-tasavvuf büyükleri gibi onun da hakkında muhtelif araştırmalar yapılmıştır.

Selçuklularla beraber Anadolu Sahası Türk edebiyatı şairleri eserlerinde, Hint-İran menşeli, Eski Fars Kültürünü yansıtan Şehname kaynaklı mitolojik ögelerden de yararlanmışlardır. Klasik Türk edebiyatı şairleri özellikle Türk hükümdarlarına sundukları kasidelerinde bu malzemeden yararlanarak Türk hükümdarlarını daha çok İran'ın efsânevi kahraman ve hükümdarlarıyla karşılaştırma, Türk hükümdarlarını övme ve üstünlük unsuru olarak yararlanıp kullanmışlardır. Böylece klasik Türk edebiyatı şairleri sözlü anlatı kültürünün tarihi-efsanevi-mitolojik söylem zenginliğini şiirlerine taşıyp, şiirlerine anlatım zenginliği yanında anlam derinliği de kazandırmışlardır. Halk sözlü kültürüne de vakıf olan tekke ve tasavvuf edebiyatının bilge-mutasavvıf şairleri, esasen Şehname kaynaklı malzemeye vakıf olmalarına karşılık dünyevi zevk ve yaşantıdan uzak felsefeleri sebebiyle kaside türüne pek iltifat göstermediklerinden, söz konusu şehnâme kaynaklı malzemeye pek ihtiyaç duymamışlardır. Ancak, Erzurumlu İbrahim Hakkı Divanı'nda görüldüğü üzere mutasavvıf şairlerin eserleri incelenip analiz edildiğinde Şehname kaynaklı kültür birikimine tamamen duyarsız kalmadıkları da görülmektedir.

\section{Erzurumlu İbrahim Hakkı Hakkında Kısa Bir Bilgi}

Erzurumlu İbrahim Hakk1, “2 Muharrem 1115’te (18 May1s 1703) Erzurum'un Hasankale ilçesinde doğdu. Babası Derviş Osman Efendi, aralıklarla otuz yıl kadar süren iyi bir eğitim görmüştür. Annesi, Hasankale'nin ileri gelenlerinden Dede Mahmud'un kızı Şerîfe Hanîfe Hanım'dır. İbrâhim Hakkı'nın "Hakîrullah" diye andığı ve "hilm ü hayâ madeni”" olarak tanıtı̆ğ babası bazı maddî ve ruhî problemler sebebiyle sıkıntılı bir dönem yaşamış, İbrâhim Hakkı'nın doğumuyla bir ferahlık hissetmekle birlikte sıkıntısı devam etmişti.

1119 'da (1707) Erzurum'a yerleşen Osman Efendi burada yörenin ileri gelen ilim ve tasavvuf erbabıyla tanışmış ve 1122 'de (1710) hac niyetiyle yola çıkmışken Siirt'e yaklaşık 7 km. uzaklıkta bulunan Tillo'ya (bugünkü Aydınlar) uğramış, yörenin tanınmış mürşidlerinden İsmâil Fakîrullah'a intisap ederek buraya yerleşmiş, böylece yıllardır aradığı huzura burada kavuşmuştur. Babasının isteği üzerine dokuz yaşında iken amcası Ali tarafından Tillo'ya götürülen İbrâhim Hakkı babasıyla karşılaştığında şeyhi İsmâil Fakîrullah'1 da orada gördüğünü, içinde ona karşı derin bir sevgi ve hayranlık duygusu uyandığını ifade eder. Bundan sonra İsmâil Fakîrullah'ın babası için yaptırdığı, günümüze kadar ayakta kalan hücrede yaşamaya başlamış, İsmâil Fakîrullah'ın ilim ve irfanından istifade etmesi yanında Mârifetnâme'deki ifadesiyle "peder-i azîzi kendisini hücredaş edip hilm ü rıfk ile ilim öğretip lutufla terbiye kılmıştır." Bu ifadelerden İbrâhim Hakkı’nın ilk tasavvuf zevkini babasından aldığı anlaşılmaktadır.

1160 (1747) yılında İstanbul'a giden İbrâhim Hakkı, şeyhi Fakîrullah'ın Sultan I. Mahmud nezdindeki saygınlığından faydalanarak padişahla görüşüp ilgi ve takdirini kazandı, saray 
kütüphanesinde çalışmasına izin verildi. Özellikle yeni astronomiye ilgisinin bu kütüphanedeki çalışmalarıyla başladığı söylenebilir. İbrâhim Hakkı İstanbul'da iken kendisine müderrislik pâyesi verildi ve ders okutması şartıyla Erzurum'daki Abdurrahman Gazi Dede Tekkesi'nin zâviyedârlı̆̆ 1 tevcih edildi. Erzurum'a döndükten sonra Habib Efendi Camii'ndeki imamlık görevini sürdüren İbrâhim Hakkı, bir müddet sonra aynı zamanda iyi bir mûsikişinas olan oğlu İsmâil Fehim'in tahsilini tamamlaması üzerine bu görevi ona bırakarak ilmî faaliyetlere daha fazla zaman ayırabilmek için günlerinin çoğunu Hasankale'de geçirmeye başladı.

İbrâhim Hakkı 1168'de (1755) resmî bir hizmet için İstanbul'a çağırılan Erzurum gümrükçüsü Mehmed Sun'ullah ile birlikte ikinci defa İstanbul'a gitti. O, ilkinden daha uzun sürdüğü anlaşılan bu ikinci ziyaret sırasında da kütüphane çalışmaları yapmış olmalıdır. Nitekim Mârifetnâme'yi İstanbul dönüşünden kısa bir süre sonra tamamlaması (Zilhicce 1170 / Ağustos 1757), onun bu eserle ilgili olarak İstanbul'da yoğun bir hazırlık çalışması yaptığı kanaatini vermektedir. İbrâhim Hakkı, Hasankale'ye dönünce bir yandan Mârifetnâme'nin telifiyle meşgul olurken bir yandan da öğrenci yetiştirmeye başladı. Abdurrahman Gazi Dede Tekkesi'nin zâviyedârlığı III. Mustafa tarafindan 1173 (1760) yılında yenilendi. İbrâhim Hakk1, tekkenin oldukça kısıtlı olan gelirini oğulları ile amcasının oğlu Yûsuf Nedim arasında paylaştırdı. İbrahim Hakk1 19 Cemâziyelâhir 1194 (22 Haziran 1780) tarihinde vefat etti” (Çağrıcı, 2000: 305-311).

Erzurumlu İbrâhim Hakkı'nın eserlerinin dili üslubu ve anlam çerçevesi ve derinliği birlikte değerlendirildiğinde iyi bir tahsil gördüğü eserlerinden anlaşılmaktadır. Onun "Bu zamanda en dürüst dost, en uygun meclis arkadaşı, en seçkin yoldaş, yârların en hayırlısı ve sevgililerin en sevgilisi kitaplar olduğu için bunların sohbetlerine meylimi salmışımdır" (Çağrıcı, 2000: 305-311) ifadesiyle devrinin geçerli medrese eğitimi ve öğretimi yanında zamanının çoğunu kütüphanelerde kitap okuyup kendini yetiştirdiğini söylemek mümkündür. O sadece dînî ahlâkî konulara ilgi duymamış; bunların yanında astronomi, tıp, anatomi, fizyoloji, aritmetik, geometri, trigonometri, felsefe, psikoloji konularına da ilgi ve alâka duyarak ileri bir düzeyde kendini yetiştirmiştir.

18. yüzy1lda eserler veren Erzurumlu İbrahim Hakk1 Hazretlerinin okuma ilgi ve merakı da dikkate alındığında, kendisinden önceki yüzyıllarda eser veren divan ve tekke edebiyatı şairlerinin eserlerinden haberdar olduğu, bir kısmını okuduğu, takdir ettiği ve etkilendiği kabul edilebilir bir gerçekliktir.

Oğuzların Selçuklu Devleti ile İran coğrafyasından geçerek geldikleri Anadolu'ya Fars dili ve kültürünü de taşıdıkları bilinmektedir. Selçuklu yüksek zümresinin Anadolu'ya taşıdığı dil ve kültür; İran'da bulundukları sürede yakından tanıyıp benimsedikleri Fars kültürü ile karışıp kaynaşmış bir Türk dili ve kültürü halinde idi. Bu kültürel olgunun tipik örneği olarak Mevlânâ Celâleddîn Rûmî kabul edilebilir. Ortak bir söylem dilinden söz edemesek de; mutasavvıf şâirler arasındaki felsefî̀ duyuş ve düşünüş benzerliğinden söz etmek mümkündür. Mesela, Mevlana'nın ölüm gerçekliğini “şeb-i arus” olarak niteleyen yaklaşımına İbrahim Hakkı:

"Halk ölüm sandığı hoş vuslat imiş ey Hakkı

İyd-i ekberdir o, sanma ki mematım geldi” (Külekçi \& Karabey, 1997: 20) 
Beytiyle "iyd-i ekber" (En büyük bayram) gibi yeni bir yorumla dile getirir. Bu ölümü benzer bir ifadeyle tanımlama, Mevlana ile Erzurumlu İbrahim Hakkı arasındaki duygusal, düşünsel ve kültürel yakınlık ve etkileşimin bir sonucu olarak kabul edilebilir. İki şair arasındaki bu ilgi ve alakadan hareketle İbrahim Hakkı'nın da Mevlânâ'yı okuduğu, sevdiği ve şiir malzemesi olan Fars kültürüne vâkıf olduğu kabul edilebilir.

Anadolu Selçuklularından başlamak üzere, Osmanlı saray çevresinde bulunan şâir zümresinin aldıkları eğitim ve öğretimle Arapça ve dini ilimler yanında; Farsça ve Fars kültürünü bilen, Bu kültürü sanat malzemesi olarak kullanabilecek düzeyde bilgi, birikim ve kabiliyete sahip oldukları malumdur. İbrahim Hakkı da "sadece dini-tasavvufi manada ilim tahsil etmiş bir âlim ve şair değil, devrine göre tıp, astronomi, matematik, fizik, gibi müsbet ilimlerle de uğraşan bir fen adamıdır (Külekçi \& Karabey, 1997: 20).

İbrahim Hakkı'nın hem pratik hem de teorik olarak yazılı kaynaklardan edindiği tasavvuf bilgisi, yazdığı eserlerinde onun yazı ve konuşma dilindeki yetenek ve kabiliyeti ile birleşince halkın anladığı, beğenip sevdiği, okuyup öğrendiği eserler olarak büyük ilgi görmüştür. Erzurumlu İbrâhim Hakkı, dünyaya meyl eden bir tabiatta olmadığı için sahip olduğu konumu ilmî ve tasavvufî birikimini maddî menfaat temini için kullanmamış kendi el emeği ve babadan kalma birkaç parça arazinin geliriyle geçinmeye çalışmış, ömrünü oldukça kısıtlı imkânlar içinde yaşamıştır.

Erzurumlu İbrahim Hakkı dînî ve bilimsel birikimi yanında XVIII. yy. Türk Tekke ve Tasavvuf Edebiyatının da önde gelen büyük şâirlerinden biridir. İbrahim Hakkı üretken bir şairdir. Kendi ifadesiyle (Külekçi \& Karabey, 1997: 20) nazım ve nesir sahasında on beş eseri bulunan şair aynı zamanda bir tasavvuf büyügüdür. Erzurumlu İbrahim Hakkı eserlerinin beşini asıl, on tanesini de ikinci derece olmak üzere iki kategoriye ayırmış asıl eserlerinin başında da Türkçe Divanını saymıştır (Külekçi \& Karabey, 1997: 20-21). Bu tasnif ve tavsiften hareketle manzum eserlerinden Divanını, onun şairlik kariyerini ortaya koyduğu en önemli eseri olarak kabul etmek mümkündür. Divan; tevhid, na't, münacat olarak yazılmış kasideler, 116 beyitlik vasiyetname ve 366 gazel, k1t'a, muhammes, müseddes, müstezat ve müfredlerden oluşan hacimli bir eserdir. Nazım şekilleri, hacmi ve dış yapı özellikleriyle Klasik edebiyat özellikleri taşıyan eser; dinitasavvufi muhtevası ve dil özellikleri ile Tekke Edebiyatı ürünlerinden biridir. Eserinde klâsik ve dînî-tasavvufî iki edebi geleneğin özelliklerine rastlanan Erzurumlu İbrahim Hakkı hem Klasik edebiyat (Külekçi \& Karabey, 1997: 24) hem de tekke edebiyatı (Banarlı, 2004: 796) şairlerinden biri olarak kabul edilmiştir. Klasik ve Tekke edebiyatı geleneğinin kaynak ve kültürel zenginliklerine vakıf olan İbrahim Hakkı'nın, eserlerinde bu malzemeden eşit biçimde yararlanmadığı söylenebilir.

Fars dil ve kültürüne ait önemli bir eser olan Şehname kaynaklı unsurların Türk şairlerince şiir malzemesi olarak kasidede yoğun kullanıldığı söylenebilir. Selçuklular devrinden başlamak üzere "Kaside, fevkalâde kültürlü insanların anlayabileceği kavramları, konuları içeriyor sanki onlara hitâp için yazılıyordu" (Çavuşoğlu, 1991: 81). Özellikle Padişahlara sunulacak kasideler başta olmak üzere, devlet ve din büyüklerini övmek için yazılan kasidelerde memdûh, Hint-İ́ran mitolojisinin Cem, Kahraman, Zâl, Rüstem vb. kahramanlarına benzetilerek; onlarla mukayese edilerek övülüp ve yüceltiliyordu. 


\section{Problem Cümlesi}

Çalışmamızda mutasavvıf bir şâir olarak İbrahim Hakkı Hazretlerinin divanı bağlamında Klasik edebiyatın kültürel kaynak ve önemli malzemelerinden olan Şehname kaynaklı mitolojik malzemenin ne oranda ve nasıl kullandığı, bu kullanımın Erzurumlu İbrahim Hakkı'nın şiir dilinde görülen söylem zenginliği araştırılmıştır.

\section{Yöntem}

Araştırmada metne dayalı analiz yöntemi kullanılmıştır.

\section{Evren ve Örneklem}

Divan edebiyatı toplumsal kültürü meydana getiren bütün alanları kaynak olarak kullandığı için divan şairleri de çok yönlü kültür zenginliğine sahip insanlardır. Ait oldukları toplumun geçmişine uzanan, tarih, mitoloji (esâtir), masal, destan, efsâne, menkıbe, astronomi, astroloji, ilm-i kimya, ilm-i simya, din ve bu çerçevede oluşup gelişen bütün dînî ilimler çerçevesinde meydana gelen günlük hayat, divan edebiyatının ilgi ve bilgi alanı içerisinde yer alır. Bu alanlara ilişkin olarak kullanılması veya ima edilmesi söz konusu olan bir husus bazen bir telmih, bazen bir mazmun, bazen de bir teşbih unsuru olarak kullanılmıştır. Divan ebiyatında adı geçen kişi, hayvan, mekân, zaman, bitki ve nesnelerin mitolojik bir geri planı mevcuttur. Bu durum bize Divan şiirinin kültürel zenginliğini, bunların şiirde uygun bir dil ile sanat malzemesi olarak kullanılması da divan şairlerinin kültürel donanımlarını, bu malzemeyi kullanma başarıları da, şairin şiir vadisindeki kabiliyet ve kapasitelerini yansıtan bir ölçü olarak görülebilir.

Tarihin derinliği içerisinde mitoloji ile efsanenin iç içe geçtiği de bir gerçektir. Tarihsel süreçte târihî-efsanevi şahsiyetlerin hayatları etrafinda oluşturulan efsâneler, kişilerin tarihsel kimliklerini mitolojik bir şekle çevirmiş gibidir. Divan şairleri de söz konusu malzemeden halk söylencelerinde yer aldığ 1 şekilde yararlanmışlardır (İnce, 1992; Tökel, 2000: 1). İbrahim Hakk1 Divanı'nda kasideler ve gazeller başta olmak üzere Divanın tamamında, tekrarlarıyla 23 yerde tespit edilen sınırlı sayıdaki Şehname kaynaklı unsurlar kullanıldıkları beyitlerle aşağıda gösterilmiştir.

\section{Bulgu ve Yorumlar}

Divan şiirinde adı geçen Şehname kaynaklı unsurlardan olmak üzere belli başlıları: BarbedNikisa, Behmen, Behram, Behzad, Bijen, Cemşid, Dahhâk, Dârâ, Efrasiyâb, Ehrimen, Erdşir, Fağfur, Feridun, Gâve, Giv, Huşeng, Hüsrev, İsfendiyar, İskender, Kahraman, Keyhüsrev, Keykâvus, Keykubâd, Kiyûmers, Leclac, Mani, Minuçihr, Neriman, Nûşiravân, Rüstem, Sam, Siyavuş, Sührab, Tahmurs ve Zâl sayllabilir (İnce, 1992: 211-233; Tökel, 2000: 114-267). Bu isimlerin yanında isimlerle doğrudan veya dolaylı olarak alakalı olan: Anka, Si-Murg, Hüma gibi mitolojik kuş ve Kaf gibi mitolojik dağ adları vb. de kullanılmıştır. Söz konusu malzeme Klasik edebiyat şairleri tarafindan, tarihte bilinen, yerleşmiş anlam ve yorumlarından yararlanılarak yeni anlatım ve söylemler için birer mukayese ve anlatımı vurgulama ögesi olarak kullanılmışlardır. İbrahim Hakkı Divanı'nda adı geçen Şehname kaynaklı unsurlar ve kullanılış biçimleri aşağıda ele alınmıştır: 


\section{Cem-Cemşîd}

İbrahim Hakkı Divanı'nda adı geçen Şehname kaynaklı şahıslardan biridir. Nuh Peygamber zamanında yaşadığı rivayet edilen Cem, Pîşdâdiyân sülâlesinin dördüncü hükümdarıdır. Zandavesta'da adı Hint mabûdu olarak da geçen Cem, edebiyatta meşhûr ve yakışıklı padişahlar için sıfat olarak kullanılmıştır. Güneş yılını kabul etmesinden dolayı, adı nevrûzla beraber de anılır. Hükümdar Cem, halkını meşgul oldukları işlere göre: âlim ve zâhitler, askerler, çiftçiler ve sanatkârlar olmak üzere dört gruba ayırmış. Efsâneye göre Cem, Dünyayı dolaşırken Azerbaycan'a gelir ve burayı beğenir. Güneşin doğduğu yerde, yüksek bir tepeye mücevherlerle süslü bir taht koydurur. Güneşin doğmasıyla taht, tâc ve kaftanın parladığını gören halk Cem'in adını "şîd" parlayan) kelimesiyle birlikte söylemeye başladıkları gibi, hâdisenin olduğu güne de "Nevrûz" demişlerdir (İnce, 1992: 213; Levend, 1980: 155-156; Pala, 1989: 175).

"Bir dahi haşmet ü Cemşid'i bana vasf etme

Ki lebi cur'a-keş-i Husrev ü Şirin’imdir” (Külekçi \& Karabey, 1997: 231) (G.95/B.6)

"Fakir-i fani eder ben Cem-i cihan oldum

Emir eder o Cem'e bende-i şüban oldum” (Külekçi \& Karabey, 1997: 397) (G.261/B.1)

Rivayetlere göre, şarabı bulan da Cem'dir. Cem, beraberindekiler ile bir kır gezisinde iken gökte bir kuş görür. Kuşun ayaklarına sımsıkı sarılmış bir yılan vardır. Okçularına kuşa zarar vermeden yılanın vurulmasını emreder. Böylece yılandan kurtulan kuş Cem'in yanına gelir ve ağzından çıkardığı bir-kaç taneyi oraya bırakır. Bu taneler ekilince asma ve dolaysıyla üzüm meydana gelir. İnsanlar üzümün suyunu içmeğe alışılar. Ancak vaktinde tüketilemeyen üzüm sularının değişen tadı, halkta bekleyen bu üzüm suyunun zehirli olduğu inancını doğurur. Bir gün intihar etmek isteyen bir câriye, zehir olarak bildiği beklemiş, köpürmüş üzüm suyundan içer. Kendisine geldiği zaman başından geçeni ve yaşadığı ruh hallerini Cem'e anlatır. Bu hâdiseden sonra Cem de şırayı bekleterek içmeyi âdet haline getirir. Daha sonra adı şarap olarak bilinen bu içeceğin tüketimi halk arasında yaygınlaşır (İnce, 1992: 214). Cem kelimesi şiirlerde yalın olarak kullanılabildiği gibi anlam bütünlüğü sağlayan kelimelerle (cam-1 Cem vb.) tamlama haline getirilerek de kullanılmıştır.

“Çün şarab-ı nab-1 irfanı içüp Cem olsa dil

Mahrem-i vahdetsin andan dime asla bir suhan” (Külekçi \& Karabey, 1997: 420) (G.284/B.2)

"Kim ki ol mest-i mey-i vahdet-i aşk olmuşdur

Tarik-i cam-1 Cem ü bade-i hamra oldı”(Külekçi \& Karabey, 1997: 489) (G.353/B.3)

"Hoş safa-bahşıdır ol cam-1 mahabbet Hakkı

Öyle bir cam-1 safa layıkı bu Cem bulunur” (Külekçi \& Karabey, 1997: 252) (G.116/B.7) 
Yukarıda örnek alınan beyitlerde mutasavvıf şair Erzurumlu İbrahim Hakkı tarafindan Cem / Cemşîd kelimeleri şarap ve muhabbet ilgisiyle kullanılmıştır. Tasavvuf terimi olarak şarap; beyitte Allah aşkına ve muhabbetine karşı1lık kullanılmıştır. Bu kullanımlar beyitlerde anlam derinlik ve çeşitliliğne imkan vermiştir.

Hüsrev:

İbrahim Hakkı Divan'ında kullanılan Şehname kaynaklı şahıslardan biri de Hüsrev'dir. Bu isim Divanda yalnız bir beyitte kullanılmıştır.

Nûşirevan'ın torunu olan Hüsrev, Sâsâniyân sülalesinden bir padişah olup "Perviz" lakabıyla da anılmıştır. İran şahlarından bazıları aynı adla anılsa da içlerinde en meşhur olanı budur. Zaman içerisinde Hüsrev, "padişah" manasına kullanılan bir kelime haline gelmiştir. 589 yılında tahta geçen Hüsrev'in Ermen Prensesi Şirin'e olan aşkı dillere destan olmuş, gerçek kişiliği etrafında gelişen rivayetlerle efsanevi kişiliğe bürünmüştür. Hüsrev ü Şirin mesnevisi kahramanlarından Ferhad ile olan rekabeti ve sonunda Şirin2e kavuşması ile meşhurdur. Sevgilisi için "Kasr-1 Şirin"i yaptıran Husrev'in "Genc-i Şâyegân" ve "Genc-i Badâver" gibi adlarla bilinen yedi hazinesinin olduğu rivayet edilir (İnce, 1992: 220).

"Bir dahi Haşmet ü Cemşid'i bana vasf etme

Ki lebi cur’a-keş-i Husrev ü Şirin'imdir” (Külekçi \& Karabey, 1997: 231) (G.95/B.6)

\section{Anka (Si-Murg):}

Edebi eserlerde anlatım aracı olarak kullanılan bir unsurdur. Efsaneye göre; Kaf dağında yaşadığı kabul edilen, tüyleri renkli, yüzü insana benzeyen, yere konmayan, yüksekte uçan yüce makamlı bir kuştur. Bu özelliği itibariyle halk arasında makamı yüce insanlar için, yüce makam bağlamında devlet kuşu olarak bilinmiştir. Devlet büyüklerine sunulan kasideler münasebetiyle, divan şiirinde Anka kuşu ile ilgili olarak rivayetler telmihen yer almıştır. "Simurg" olarak da bilinip kullanılan ankanın karakteristik özelliği, Kaf dağında yaşaması, renkli tüyleri, alçak yerlere tenezzül etmemesi, üst makamlı olması, avlanamayışı ve ele geçirilemeyişi olarak sayılabilir. Şiirlerde bu özelliklerinden biri veya birkaçını çağrıştıracak şekilde teşbih, mecaz ve telmih ilgisiyle yer almıştır.

"Kaf-1 dilde olmuşum 'anka-misal

Kerkes -i Murdar-harı istemem” (Külekçi \& Karabey, 1997: 398) (G.262/B.5)

"Simurğ-1 Kuh-1 Kaf-1 can bir dane 'aşkından revan

Candan düşer dama heman ol derd imiş dermanımız" (Külekçi \& Karabey, 1997: 297) (G.161/B.2)

"Vadi-i dilde tereddüd eden olmaz mahrum

Ki o Simurg'dan ol Kaf'da perr bulmuşlar” (Külekçi \& Karabey, 1997: 254) (G.118/B.5) 
“Güzel 'anka gibi gel küh-1 Kaf'a

Niçün her bum-1 şuma yar olursun” (Külekçi \& Karabey, 1997: 434) (G.298/B.6)

Şehnameye göre, Zaloğlu Rüstem'i Kaf Dağında Anka beslemiş büyütmüştür. Varlığı bilinen kendisi görülmeyen sevgililer Anka'ya teşbih edilerek işlenmiştir. Dini-tasavvufi şiir söyleyen şairler için bu bağlamda kullanımı kavramın tercih edilme sebeplerinden biri olmuştur.

"Ma'azallah ki murğ-1 can demirden bir kafes ister

Te'alallah ki 'ankanın yeri teng aşiyan olmuş" (Külekçi \& Karabey, 1997: 312) (G.176/B.6)

(Allah korusun ki can kuşu demirden bir kafes ister; yüce Allah ki ankanın yeri uygun yuva olmuş.)

Hüma:

Anka ve Simurg ile karıştırılan bir kuştur. Kaf dağında veya bilinmez diyarlarda yaşadığına inanılan efsanevi bir kuştur. Cennet kuşu olarak da bilinen Hüma, serçeden biraz büyük, yeşil kanatlı, sarı gagalı kuştur. Ayaksız olduğuna inanılan Hüma gökte uçarken gölgesi kimin üzerine düşerse o kişinin ilerde padişah olacağına inanılırmış. Bir meydanda uçurulan Hüma, kimin başına konarsa o padişah olarak seçilirmiş.

"Seyr eyle sen gönülde Hüma cilve-gahını

Hakki şikesten-i kafes asan olur sana” (Külekçi \& Karabey, 1997: 165) (G.29/B.7)

Anlatılardan ve rivayetlerden hareketle edebiyatta Hüma; Devlet makam ve kudretinin elde edilmesi, ikbalin, refah, zenginlik ve baht düzgünlüğünün sembolü olarak kullanılmıştır. Kelime kullanım sırasında tek olarak kullanılabildiği gibi anlam bütünlüğü sağlayan kelimelerle tamlama haline getirilerek de kullanılmıştır.

Kaf:

Dünyanın etrafını sardığına inanılan aşılmaz dă̆ zincirine verilen addır. Bir inanışa göre İnsanı Hakk yoldan çevirecek kötülükler bu dağın arkasındadır. Edebiyatta kullanılma sebep ve ilgisi: Yüksekliği, uzaklığı ve ihtişamı ile olmuştur. Anka ile birlikte kullanıldığında istiğna (doygunluk) ve kanaatin sembolü olmuştur.

"Simurg-1 kuh-1 Kaf-1 can bir dane 'aşkından revan

Candan düşer dama heman ol derd imiş dermanımız" (Külekçi \& Karabey, 1997: 297) (G.161/B.2)

"Kuh-1 Kaf olsan dahi gökler gibi

Ben seni rakkas u gerdan eylerim” (Külekçi \& Karabey, 1997: 382) (G.246/B.3)

“Güzel 'anka gibi gel küh-1 Kaf’a 
Niçün her bum-1 şuma yar olursun” ( Külekçi \& Karabey, 1997: 434) (G.298/B.6)

Tasavvufta Kaf Dağı mürşid-i kâmilin vücududur. Kelime yalın olarak kullanıldığı gibi Kuh-1 Kaf şeklinde bir tamlama olarak da kullanılmıştır. Dini-tasavvufi şiirlerde, tasavvuf yolunun aşılması zor ve çetin şartlarını çağrıştırmak ilgisiyle kendisine sıkça yer bulmuştur. ünyayı çepeçevre kuşatan dağın adı olarak da kabul edilir. Bu dağın ardında, efsaneye göre, cinler yaşamaktadır. Tasavvuf erbabına göre, "Kâf", Kur'ân'a işarettir. Ki bu da, Allah'ın bütün isimlerinin zuhur yeri olan ve bu mazhariyeti bilen ve bildiren insan-1 Kâmil'dir. Halk arasında Kâfdağı veya Kâf ifadesi sınırsızlık ve büyüklük manalarına kullanılır. Gururlanıp böbürlenen insanlara bunun için "burnu Kâf dağında" denir.

\section{Sonuç ve Tartışma}

Divan edebiyatı; toplumsal hayatı ilgilendiren hemen her türlü yazılı ve sözlü kültürel kaynaktan yararlanmıştır. İnsanlığın sosyo-kültürel mirası olan mitoloji de bu kaynaklardan biridir. İran dil ve kültürü, tarihsel süreçte Türk dili ve Türk edebiyatı üzerinde kalıcı izler bırakmış, Divan edebiyatı şiir dilinin şekillenmesinde de etkili olmuştur. Klasik edebiyat şairlerinin kasidede çok kullandığı Şehnâme kaynaklı Fars dil ve kültür malzemesinin, hem Klasik edebiyat hem ve Tekke tasavvuf edebiyatı geleneğini bilen ve bu geleneğe uygun eserler veren İbrahim Hakkı'nın divanında bu malzemeyi aynı oranda kullanmadığı görülmüştür. Bu gerçekliğin sebepleri irdelendiğinde: Klasik edebiyat şairlerinin duyuş-düşünüş ve yaşama biçimleriyle, tekke ve tasavvuf şairlerinin duyuş-düşünüş ve yaşam biçimleri arasındaki farklılıklar olarak değerlendirilmiştir. Klasik edebiyat şairlerinin dünyevi hayatlarının yaşam standardını yükseltmek ve daha rahat ve daha müreffeh yaşayabilmek için devlet adamlarıyla kurmak zorunda oldukları yakın münasebet ile tekke ve tasavvuf şairlerinin dünya ve devlet adamlarından uzak durmaları sonucunu gerektiren felsefi amaç, düşünüş ve yaşayış farklarıdır. $\mathrm{Bu}$ birbirinden farklı felsefeye dayanan yaşama tercihi, kaside yazımlarında şairlerin malzeme tercihlerini de etkilemiştir. Dini-tasavvufi sahada manzum-mensur dini-edebi didaktik eserler veren İbrahim Hakkı, Klasik edebiyat geleneğini bilen ve eserlerinde bu geleneğe uygun şiirler söylemesine rağmen, divanında Şehname kaynaklı unsurlara fazla yer vermemiştir. Klasik edebiyat şairlerinin özellikle kasidelerinde yoğun olarak yararlanıp kullandıkları bu malzemenin, Erzurumlu İbrahim Hakkı Divanı'nda az kullanılmasının sebebi, söz konusu kültür birikimine sahip olmayışı değildir. İbrahim Hakkı'nın mutasavvıf bir şair olarak, zühd ve takva içinde yaşaması, bu bağlamda dünya ve devlet adamlarından bir beklenti içerisinde olmayışı, bunun için devlet büyüklerine kaside sunmayışı Şehname kaynaklı unsurların az kullanılma sebebi olarak değerlendirilebilir. Klasik edebiyat şairlerinin devlet erkânını övmek için kasidelerde teşbih ve telmih ilgisiyle çokça yer verdikleri mitoloji ve Şehname kaynaklı unsurlara, İbrahim Hakkı Divanı'nda fazla ihtiyaç duyulmamıştır. Ancak çok sınırlı da olsa bu malzemeyi birer tasavvuf terimi gibi kullanması, onun dini-tasavvufi şiir dil ve üslubuna Klasik edebiyatın söylem özelliği katmasını sağlamıştır.

Her söyleyeni dinle

Ol söyleyeni anla

Hoş eyle kabul canla 
Allah görelim neyler

Neylerse güzel eyler

\section{Kaynakça}

Altıntaş, H. (1992) Erzurumlu İbrahim Hakkı, Ankara. MEB Yayınları.

Banarlı, N. S. (2004). Resimli Türk Edebiyatı Tarihi, İstanbul: Milli Eğitim Bakanlığı Yayınları.

Binark,İ. \& Sefercioğlu, N. (1977) Erzurumlu İbrahim Hakkı Bibliyografyası, Ankara, Kültür Bakanlığı Yayınları.

Bursalı Mehmed Tahir. (2016) (Çev. M.A. Yekta Saraç) İstanbul. Türkiya Bilimler Akademisi Yayınları.

Çağrıcı, M. (2000) “İbrahim Hakkı Erzurumî” TDVİA C.XXI. İstanbul.

Çavuşoğlu, M. (1991). Kaside Şairi Nef'î Ölümünün Üçyüzellinci y1lında Nef'̂̂”, Ankara: Atatürk Kültür Merkezi Yayınları.

Çelebioğlu, Â. (1988) Erzurumlu İbrahim Hakkı, Ankara. Kültür Bakanlığı Yayınları

İbrahimhakkığlu, U. (1998) Erzurumlu İbrahim Hakkı ve İki Torunu Feyyaz Efendi ile Zakir Bey, Ankara. Bayrak Basım Yayım Tanıtım.

Genç, İ. (2005) Örneklerle Eski Türk Edebiyatı Tarihi Giriş (Başlangıçtan XVI. Yüzyıla Kadar) İzmir. Kanyılmaz Matbaası.

İnce, Ö. (1992). Cevrî Dîvânı'ndaki Tarihi ve Efsânevî Unsurların Tespiti ve İşlenişi, (Yayımlanmamış Yüksek Lisans Tezi), Dokuz Eylül Üniversitesi Sosyal Bilimler Enstitüsü, İzmir.

Köprülü, M. (1981) Türk Edebiyatı Tarihi, İstanbul 1981. Ötüken Yayınları.

Külekçi, N. \& Karabey, T. (1997). Divân Erzurumlu İbrahim Hakk1, Erzurum: Atatürk Üniversitesi Yayınları.

Levend, A. S. (1980). Dîvân Edebiyatı Mazmunlar ve Mefhumlar, İstanbul: Enderun Kitabevi.

Özyılmaz, Ö. (1986) “İbrahim Hakkı Erzurûmî’nin Tertîb-i Ulûm İsimli Eserindeki Eğitimle İlgili Görüşleri” (UÜ Sosyal Bilimler Enstitüsü, Basılmamış Yüksek Lisans Tezi), Bursa

Pala, İ. (1989). Ansiklopedik Dîvân Şiiri Sözlügü̈, Cilt: I-II, Ankara: Akçağ Yayınları.

Tökel, D. A. (2000). Dîvân Şiirinde Mitolojik Unsurlar-Şahıslar Mitolojisi, (1. Baskı), Ankara: Akçağ Yayınları. 